Presented at the SPIE 22nd International

Technical Symposium, San Diego, CA,

LBL -8022

August 28 - 31, 1978

\title{
MICROSTRUCTURE OF A BLACK CHROME SOLAR \\ SELECTIVE ABSORBER
}

Car1 M. Lampert

August 1978
WEE E IVED DAWRENCE

BCRKFEY IABORATOKY

00 T. 31978

LIBRARY AND DOCUMENTS SECTION

Prepared for the U. S. Department of Energy under Contract $W$-7405-ENG-48

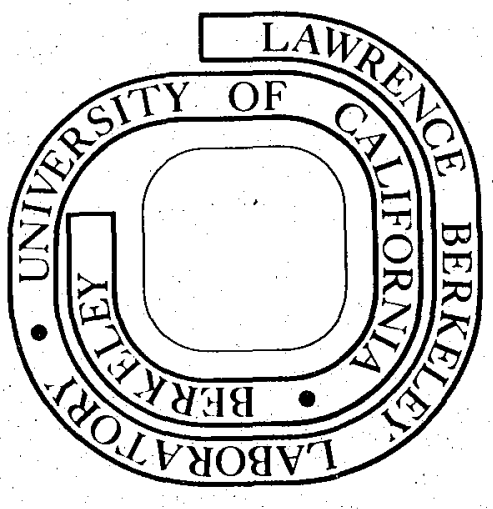


LEGAL NOTICE

This report was prepared as an account of work sponsored by the United States Government. Neither the United States nor the Department of Energy, nor any of their employees, nor any of their contractors, subcontractors, or their employees, makes any warranty, express or implied, or assumes any legal liability or responsibility for the accuracy, completeness or usefulness of any information, apparatus, product or process disclosed, or represents that its use would not infringe privately owned rights. 
MTCROSTRUCTURE OF A BLACK CHROME SOLAR SELECTIVE ABSORBER

\author{
Car 1 M. Lampert \\ Matexials and Molecular Research Division \\ Lawrence Berkeley Laboratory \\ and \\ Department of Materials Science and Minexal Engineering \\ College of Engineering: University of California \\ Berkeley, California 94720
}

\begin{abstract}
The structure of Harshaw Chemicals" "CHROM-ONYX" type of black chrome/metal selective absorber was studied to gain a better understanding of its influence upon the mechanism of wavelength selectivity. Spectral reflectance measurements were performed on seven samples. In this study, the best selectivity was found by these measurements to be 1.0 micron of black chrome on copper and 0.7 micron of black chrome on nickel. Both transmission and scanning electron microscopy were employed to study microstructure and chemical composition. As a result of the combined studies, some effects of black chrome thickness and the metallic substrate were determined. It was found that black chrome consisted of a very fine metallic distribution of paxticles of chromium, possibly suspended within a matrix of an oxide of chromium. This combination was, in turn, agglomerated into larger particles within the $0.05-0.3$ micron size range. These larger particles formed a network which constituted the surface coating.
\end{abstract}

\title{
Introduction
}

There are many candiates for solar collector absorber coatings, which are used for heating of various fluids including air, and in some cases, the production of steam. There are two major divisions of the many available coatings, the selective and non-selective types. Selective coatings in general are more efficient and offer lower heat losses and higher operating temperatures than do non-selective coatings. Selectivity is produced by a substance that exhibits optical properties which vary greatly from one spectral region to another. A solar selective surface efficiently captures solar energy in the high intensity visible and the near infrared spectral regions while maintaining poor infrared radiating properties. Accordingly, a selective surface will absorb and retain a high amount of energy from the sun while a non-selective surface will lose much of its absorbed energy by re-radiation. Fox optimum efficiency the solar absorber should possess the maximum possible absorptance in the solar spectrum while exhibiting the minimum infrared emittance. In most cases high absorptance is obtained by a black surface coating and low emittance is procured by use of an underlying highly reflective metal layer. Although selective coatings have superior optical properties and exhibit high efficiency compared to other coatings, very few show promise of being economical. One coating showing promise is called black chrome. of the different types of black chrome the commercial coating, "CHROM-ONYx", a decorative finish manufactured by Harshaw Chemical Company, has been of interest to various investigators. The basic solar selective properties have been investigated using spectral reflectance measurements. (1) This surface also has been compared and life-tested (2) relative to othex selective coatings such as black nickel. $(3-5)$

A typical relationship between absorbed energy and emitted energy by a selective surface is depicted in Figure 1 . This figure represents the generalized wavelength selectivity property of black chrome with respect to the aix mass 1 solar terrestrial spectrum $(6)$ and $100^{\circ} \mathrm{C}, 300^{\circ} \mathrm{C}$ blackbody spectra. Little is known about the mechanism of selectivity for black chrome. It has been suggested that such a surface may perform according to the Mie or Maxwe11-Garnet theory. (7) But these theories are not yet refined enough to take account of such a complex surface as black chrome. The first step in understanding the mechanism of solar energy collection by this surface is to investigate the relationship between the microstructure and optical properties. The following study presents a characterization of "CHROM-ONYX" black chrome in terms of material science.

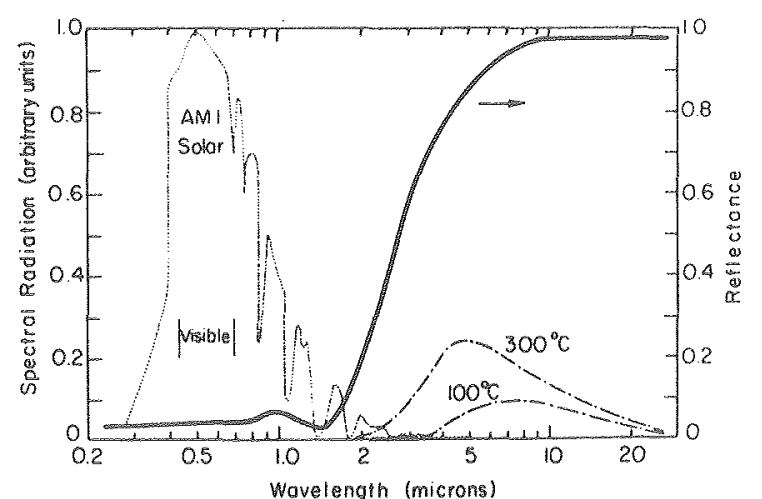

Fig. 1. Wavelength relationship between black chrome spectral reflectance, the solar spectrum and blackbody spectrum $\left(100^{\circ} \mathrm{C}, 300^{\circ} \mathrm{C}\right)$. 


\section{Experimental Procedures}

In this study copper and steel test panels were electroplated with black chrome by the Harshaw chemical Company, according to the following procedure:
1) Clean by an electrolytic alkaline kelating process, $88^{\circ} \mathrm{C}$ at 76 and $86 \mathrm{~mA} / \mathrm{cm}^{2}$, two cycles.
2) Nickelplate (dull finish, Harshaw NUSAT treatment) to thickness of about 12.7 microns.
3) Black chrome (CHROMmONYX) plate, $216 \mathrm{~mA} / \mathrm{cm}^{2}, 24^{\circ} \mathrm{C}$ for $2-4$ minutes at 24 volts.
4) Water rinse, alcohol rinse and dry.

Process step (2) is omitted for some samples. The plating time in step (3) can be adjusted to a desired thickness The relationship between deposit thickness and time has been determinted experimentally.(8) By use of the foregoing plating procedure the samples listed in rable 1 were produced.

Table 1. Samples for Black Chrome (BC) Study.

1. Stee1 Substrates

R1 - 1.0 micron $\mathrm{BC}$ on 12.7 microns Nickel, on steel

R2 - 0.9 micron $B C$ on 12.7 microns Nickel, on steel

R5 - 0.7 micron $B C$ on 12.7 microns Nickel, on Polished steel

R16 - 1.0 micron BC on stee 1

2. Copper Substrates

R4 - 1.0 micron $B C$ on 12.7 microns Nickel, on Copper

R9 - 1.0 micron $B C$ on Copper

R17 - 0.7 micron $\mathrm{BC}$ on 12.7 microns Nicke1, on Copper

Spectral reflectance measurements were used to investigate the optical selectivity of each sample. All reflectance measurements for the wavelength range $0.28-1.8 \mathrm{microns}$ (visible and near infrared) were done on a Cary 14 integrating spectrophotometer. The measurements for the wavelength range $2.0-25$ microns (infrared) were performed on a Gier-Dunkle model HC300 heated cavity reflectometer with an SP210 absolute directional integrating sphere. All reflectance measurements were taken at near normal (200 C) incidence.

The surface and cross sectional morphology of the specimens were characterized by use of AMR 1000 scanning electron microscope (SEM). Qualitative elemental analysis was determined by energy dispersive $x$-ray analysis (EDAX).

Transmission electron microscope specimens were cut from larger samples by mechanical punching. The resulting $3 \mathrm{~mm}$ discs were ion milled with Art ions from a Commonwealth IMMI model III milling machine. The thinned specimen was examined by a Philips EM 301 research electron microscope (TEM). By use of gun tilt dark field techniques a particle size distribution had been obtained. A Zeiss Particle Size Analyzer was used with the circumscribed circle technique for particle sizing. The data was plotted in size classes representing 36 \& diameter intervals.

\section{Results and Discussion}

This section is divided into three parts. The first concerns spectral reflectance measurements, the second, scanning electron microscopy, and finally, transmission electron microscopy. These results will be correlated to form a chemical, structural and optical model of the black chrome absorber.

\section{Spectral Reflectance Measurements}

Reflectance measurements are used to derive both absorptance $\left(a_{w}(m, p)\right)$ and emittance $\left(e_{w}(m, p)\right)$ of the samples. Absorptance is the fraction of incident energy, at a given wave length $(w)$ and direction $(m, p)$, absorbed by the material. Absorptance and emittance are related by the expression $a_{W}(m, p)=e_{W}(m, p)=1-x_{W}(m, p)$ where $r_{W}(m, p)$ is reflectivity at wavelength (w) and position $(m, p)$.

In practice both absorptance and emittance are average values. Integrated absorptance $\left(a_{i}\right)$ is the average absorptance at each wavelength weighted according to the solar energy intensity distribution. Net emittance (ej) is calculated by taking the average emittance at each wavelength weighted according to the blackbody intensity distribution (corresponding to the operating temperature of the surface). In Table 2 values For integrated absorptance 
and net emittance are tabulated along with $a_{i} / e_{i},\left(20^{\circ} \mathrm{C}\right)$ a figure of merit for each sample. These values are dexived from the data shown in Figure 2.

Table 2. Integrated Absorptance and Enittance $\left(20^{\circ} \mathrm{C}\right)$.

\begin{tabular}{|c|c|c|c|c|c|c|c|}
\hline Type & RI & $R 2$ & $R 4$ & R5 & R9 & R16 & RI7 \\
\hline$a_{i}$ & 0.958 & 0.951 & 0.957 & 0.932 & 0.942 & 0.92 & 0.916 \\
\hline$e_{i}$ & 0.070 & 0.065 & 0.078 & 0.046 & 0.051 & 0.070 & 0.050 \\
\hline$a_{i} / e_{j}$ & 13.7 & 14.6 & 12.3 & 20.3 & 18.5 & 13.1 & 18.3 \\
\hline $\begin{array}{l}\text { Inter- } \\
\text { Eacial } \\
\text { Layer }\end{array}$ & $\mathrm{Ni}$ & $\mathrm{Ni}$ & $\mathrm{Ni}$ & $\mathrm{Ni}$ & $\mathrm{Cu}$ & Steel & $\mathrm{Ni}$ \\
\hline $\begin{array}{l}\text { BC } \\
\text { Thickness } \\
\text { (microns) }\end{array}$ & 1.0 & 0.9 & 1.0 & 0.7 & 1.0 & 1.0 & 0.7 \\
\hline
\end{tabular}

Black chrome (BC) electroplated on copper, steel, and nickel plated samples all exhibit similar reflectance properties. The copper substrates show the same interference phenomena in the region of $0.4-1.6$ microns wavelength (Figure 2a) as noted with steel samples (Figure 2c). This interference effect is characterized by a rise followed by a fall in
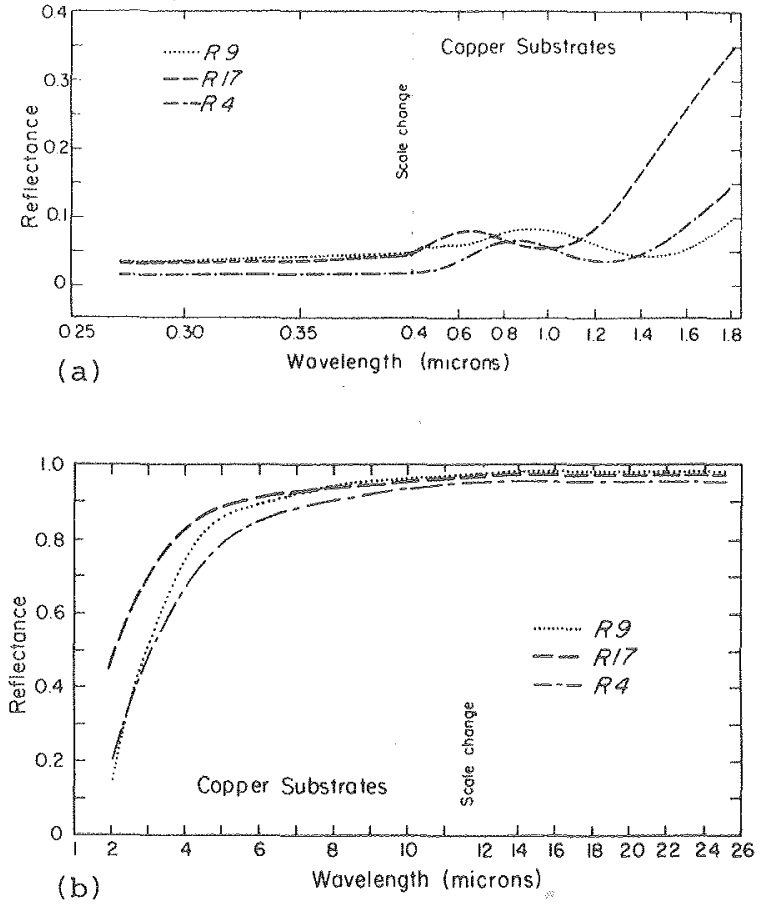

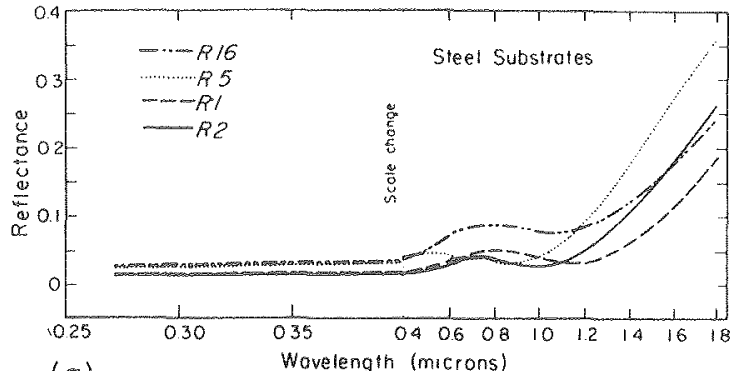

(c)

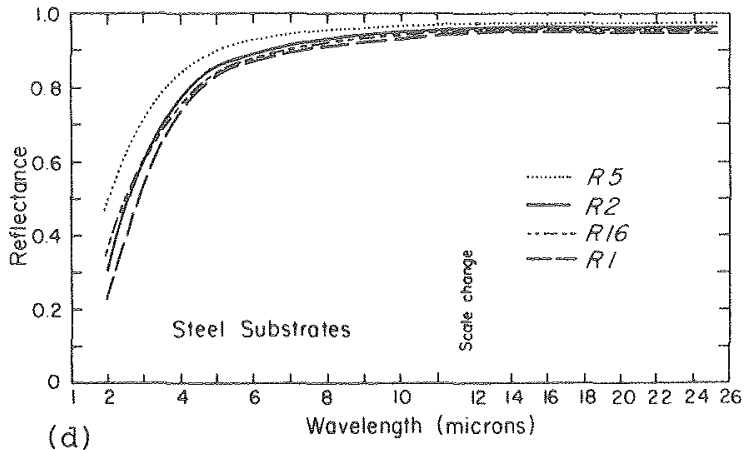

(d)

Fig. 2. Spectral reflectance measurenents for several black chrome absorbers. (a) (c): visible region for copper and steel substrates. (b), (d): infrared region for copper and steel substrates.

reflectance, in the shape of a sine wave. If the position of this sine curve is compared to $\mathrm{BC}$ coating thickness, it appears that this effect is related to thickness. The physical thickness of the coating may be different but related to the effective optical thickness, which undoubtedly is wavelength-dependent. The overall influence of the BC coating thickness upon nickel plated samples can be viewed in Figure 3. In general, the thicker the BC layer the later the transition takes place between low and high reflectivity. with the interference region moving accordingly. Samples with 0.7 microns of $B C$ show the $s t e e p e s t$ transition slope (Figure 3). Thicker layers of BC show less solar selectivity. Other investigators have vexified that optimum thickness is about $0.5-1.0$ micron [see Ref. (8), $\mathrm{pg} .3]$. 


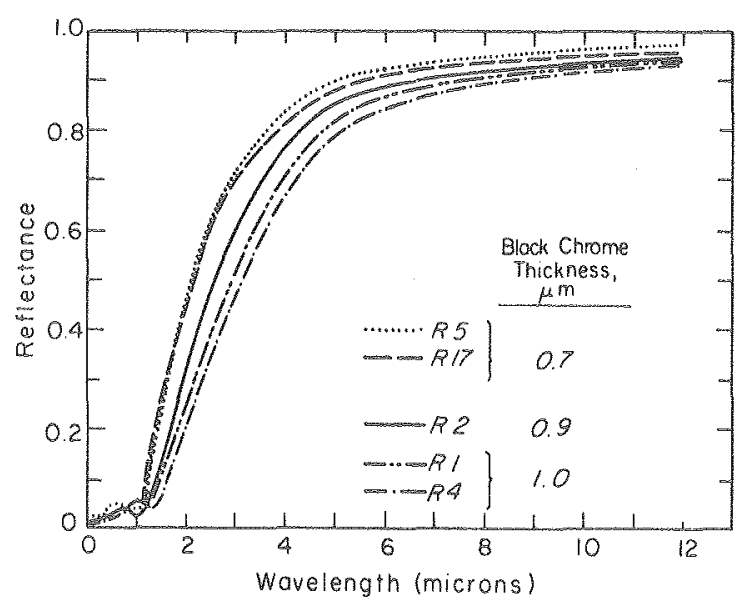

Fig. 3. Spectral reflectance for different thicknesses of black chrome on nickel plated substrates.

For $\mathrm{BC}$ on copper (R9) the transition region exhibits a sharper rise than fox the nickel and steel substrates, in that order. This order is reversed for the initial wavelength at which the transition takes place. The initial transition for sample $\mathrm{R} 9$ is at a higher wavelength (1.8 microns) than all others tested. The sharp rise may be due to the fact that the copper substrate has an inherently higher reflectance than nickel and steel. This relationship can be viewed by comparison of samples R1, R9, R16 in Figure 3. These transition effects show an optical interaction between the $\mathrm{BC}$ layer and the substrate material; but it cannot be explained merely in terms of substrate reflectance. Such effects as substrate roughness, grain size and orientation may also effect the transition region.

In conclusion, the best coatings cested were 1.0 micron $B C$ on copper (R9) and 0.7 micron $B C$ on nickel plated substrates (R5, RI7)。 RecentIy, it has been reported that copper samples not plated with nickel exhibit degradation duxing heat cycling

with the formation of copper oxide. (9) To gain a better understanding of the selectivity mechanism exhibited by the thermally stable BC on nickel absorbers the following electron microscopic investigations were perfomed.

\section{Scanning Electron Microscopy}

A typical surface morphology for BC on nickel-plated copper is shown in Figure a The particulate but physically adherent surface resembles a partially sintered powder. This surface morphology exhibiting $0.05-0.30$ micron diameter surface roughness is charactexistic of all BC surfaces tested. In Figure ta the dark "vein like" network separating dome-shaped regions of $B C$ corresponds to the grain strucm ture of the nickel layer below. The "veins" replicate the grain boundaries and other irregularities of the nickel layer. From EDAx analysis (Figure 4c) the presence of chromium and nickel was detected for the region depicted in Figure $4 b$. This analysis does not specify whether the chromium is metalid or in a compound, or what its structural form is.

Black chrome thickness for each sample was determined by SEM analysis of mechanically polished specimen cross sections. Careful regard was taken to measure the same regions which were examined by other experiments. The normal variation in thickness of the $\mathrm{BC}$ layer is shown in Figure 5b. Due to the roughness of the underlying nickel layer only average measurements of the $\mathrm{BC}$ layer were obtained. During electron bombardment the $\mathrm{BC}$ layer exhibited charging by "glowing". This charging effect is typical of electrically insulating and some semiconducting materials.

For further analysis of BC chromium content and structure, transmission electron microscopy was employed.

\section{Transmission Electron Microscopy}

Black chrome on nickel plated copper was ion thinned so the thin $\mathrm{BC}$ region could be analyzed by conventional TEM techniques. Thinned samples were also viewed by SEM to determine if damage was created during the sample making process. Damage or changes of the surface was not evident in the samples made. After thinning, the particles shown in Figure $b$ appear as a network

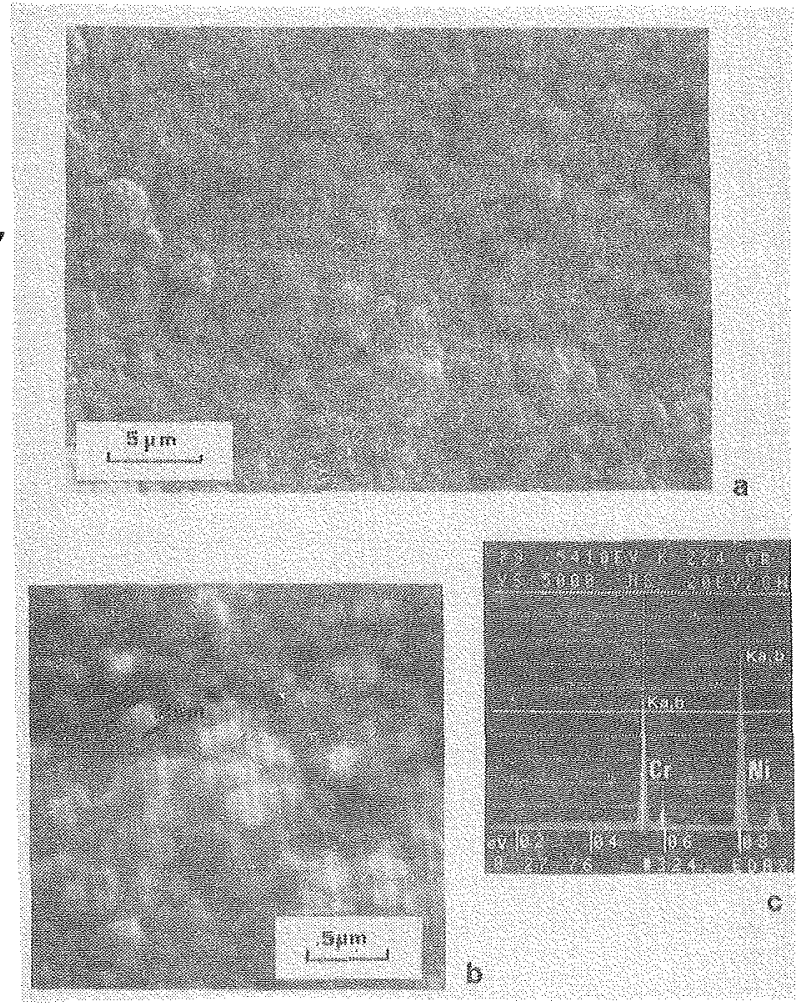

Fig. 4. Black chrome on nickel plated copper examined by SEM at $20 \mathrm{kV}, 30^{\circ}$ tilt. (a) Typical surtace microstructure: (b) detail of particles; (c) EDAX of region (b) showing chromium and nickel as principal constituents. 

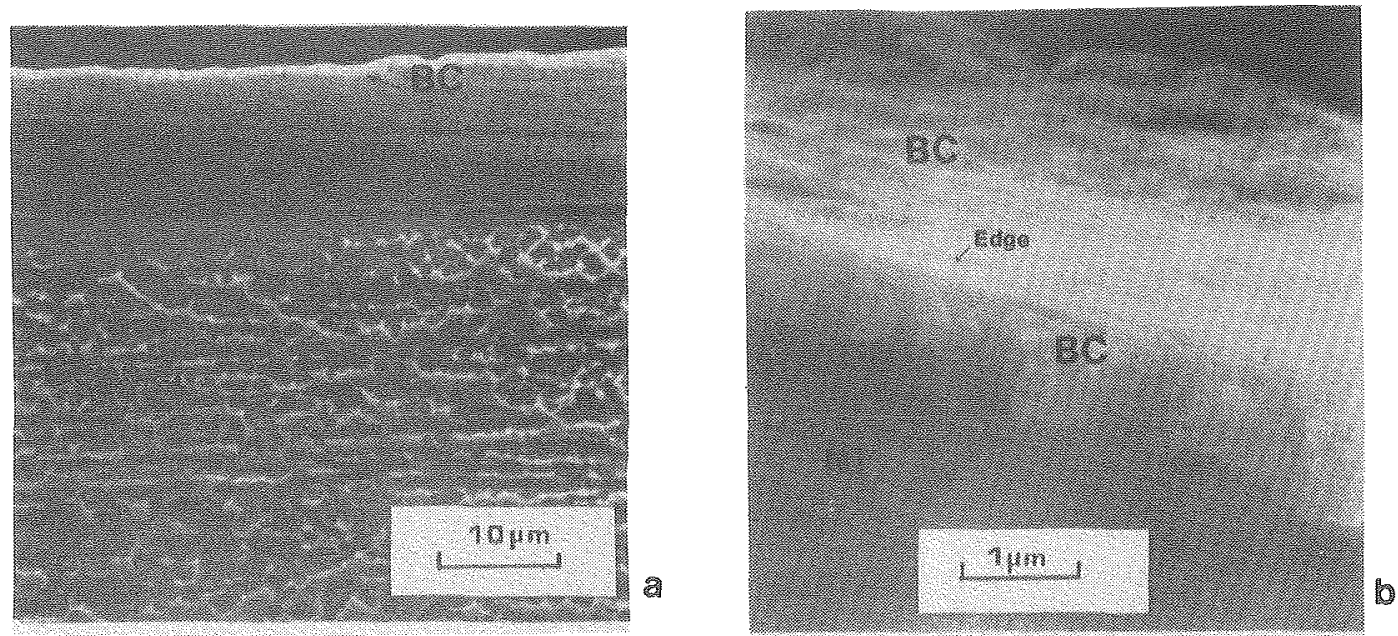

Fig. 5. Cross section of black chrome on nickel plated copper examined by TEM at $20 \mathrm{kV}, 15^{\circ}$ tilt. (a) Various layexs which constitute the selective absorber; (b) black chrome-nickel interface.

of islands represented in Figure 6a. A bright field-dark field pair is depicted in Figure 6. The diffraction pattern for this region (Figure 7) and for other regions resulted in

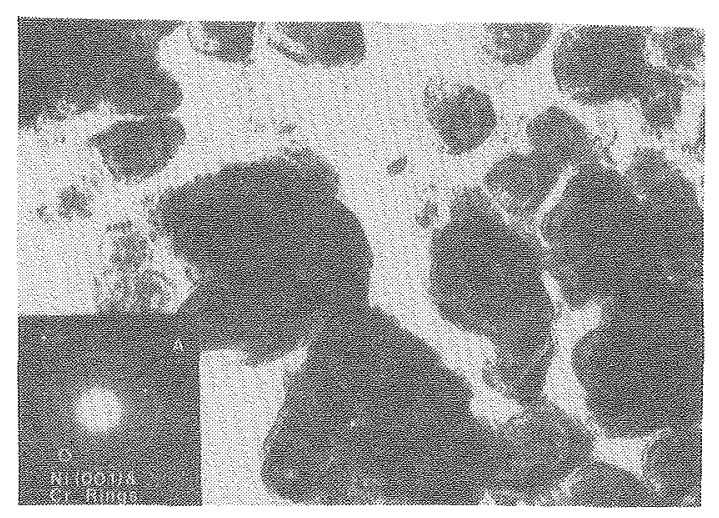

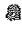

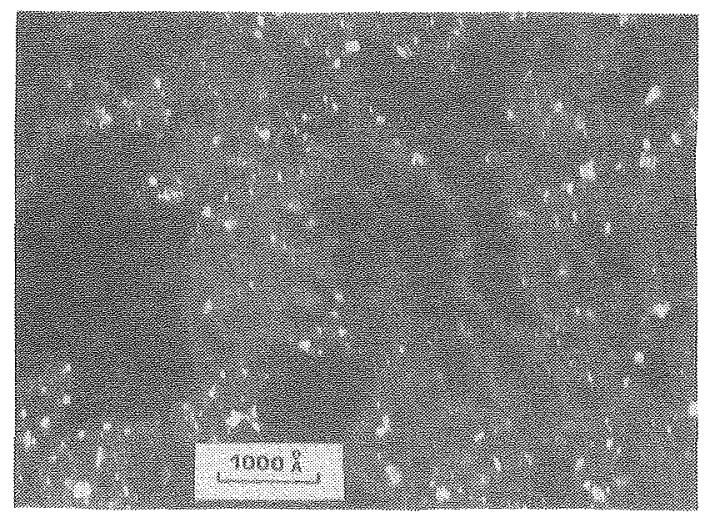

索

Fig. 6. Aggomeration of chromium particles with matris material viewed by TEM at $100 \mathrm{kV}$. (a) Bright field and diffractive pattern of black chrome islands remaining after ion thinning: (b) gun tilt daxk field of region (d) showing metal1ic chromium particles.

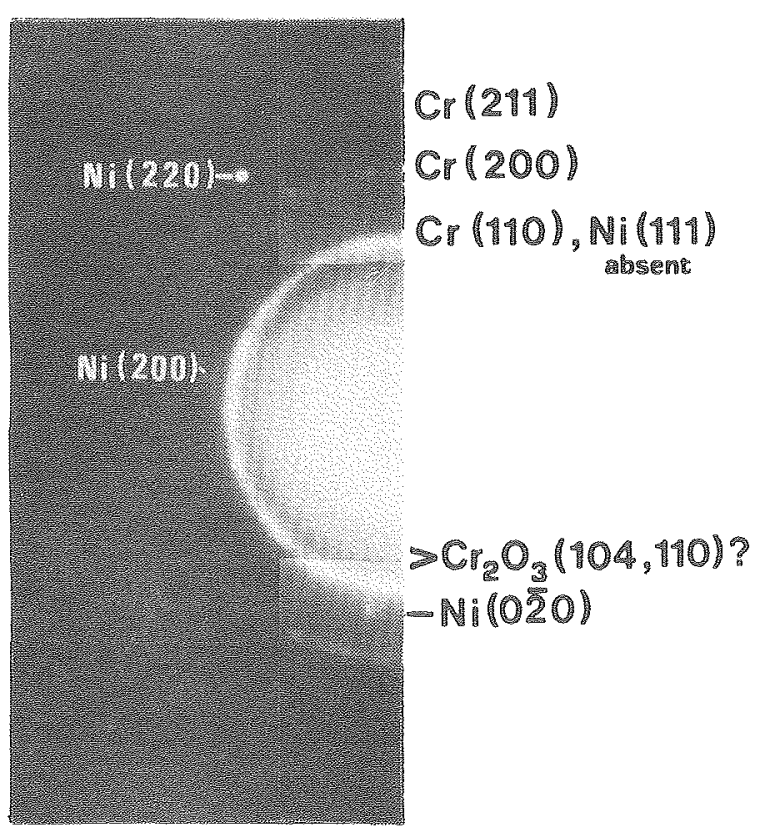

Fig. 7. Diffraction pattern for Fig. 6 showing low ordex chromium rings, single crystal FCC nickel indexed with [001] zone axis, and diffuse halo region. 
the following information:

1. Very fine crystalline chromium was identified with all rings seen up to the Cr(321) ring.

2. Residual single crystal nickel was noted; in this case the zone axis was $[001]$.

3. Two diffuse regions were noticed around the central beam. Their centers of intensity were estimated to correspond to lattice spacing (d) of 3.48 and $2.55 \%$.

In Figure 7 the diffuse halo at $2.55 \AA$ is evident but the halo at $3.4 \AA$ is not repre sented in the print. The $3.4 \AA$ halo is weak and although present in the negative it is not reproduced here. These halos correspond roughly to $\mathrm{Cr}_{2} \mathrm{O}_{3}(012)$ at $3.4 \AA$, (ASTM data $3.633 \AA$ ) and $\mathrm{Cr}_{2} \mathrm{O}_{3}(104,110)$ at $2.55 \AA$ (ASTM data $2.666 \AA$ and $2.480 \AA$ ). These halos indicate that this unknown substance lacks long range order in bonding or is to some degree amorphous. Also, by $x$-ray powder techniques weak lines of chromium have been identified along with halo regions within the lattice spacings mentioned above.

The d-spacings of the chromium and nickel agreed with ASTM data with a high degree of accuracy. Although diffraction patterns were calibrated by use of polycrystalline gold standards, the presence of nickel in the black chrome pattern serves as an internal standard. The only restriction with this technique is that if the chromium (110) ring is used for dark Fields the nickel $\{111\}$ reflections must be avoided, since their d-spacings are very close to each other $(2.04 \AA$ and 2.0348 respectively). In the case presented (Figures 6 and 7 ) nickel has a [001] zone axis, in which nickel type \{111\} spots do not occux.

The dark field pattern (Figure 6b) is representative of the size distribution of chromium particles within the larger particulate regions noted by the bright field. By obtaining many dark fields of various regions a composite particle distribution of 1358 particles was obtained. This distribution was normalized and plotted (Figure 8 ) using a relative frequency polygon technique. Each point on this plot represents an average value for each class, with the smallest interval $18 \AA^{\circ}-54 \%$. The data for sizes less than this interval is uncertain. There may exist a large number of very fine particles of chromium less than $18 \AA$. Close examination of some large particles revealed that they actually consisted of dense agglomerations of very fine particles. The distribution presented in Figure 8 should be interpreted with this uncertainty in mind. The peak particle size occurred at 72 \&ith a mean particle size of $139 \AA$.

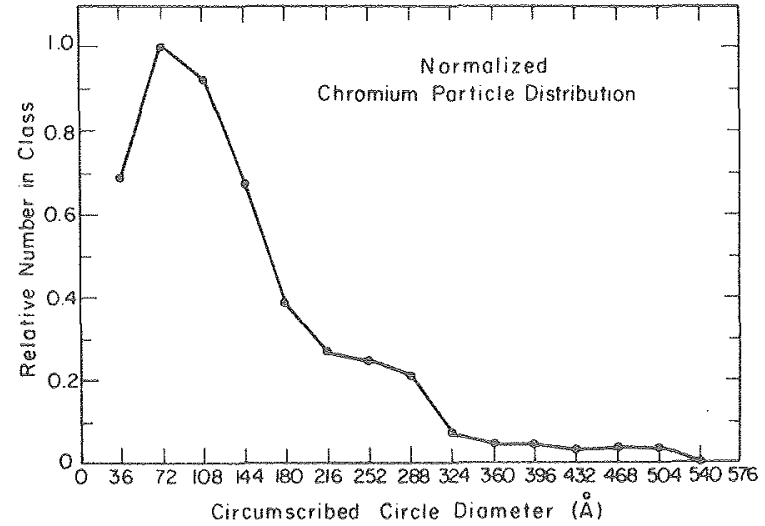

Fig. 8. Average relative frequency polygon

For chromium paxticles consisting of 1358

particles taken from various regions.

\section{Conclusions}

From this work, the following conclusions appear to be valid for the black chrome "CHROM-ONYX" solar selective absorber.

1. This surface exhibits optical propexties which can be related to black chrome coating thickness.

2. Of the selective absorbexs examined, the optical transition region from low to high reflectance occurred in general from 1.5 to 5 microns in wavelength. The increase in black chrome coating thickness shifts the transition region further into the infrared wavelengths; these thick coatings also exhibited lessened selectivity. 
3. The coatings which exhibited the best selectivity were 0.7 micron black chxome on nickel plated copper and steel and 1.0 micron black chrome plated on copper.

4. The structure of black chrome on nickel appears to consist of voids and particulate masses within the size range $0.05-0.30$ microns in diameter. These larger particles consist of even finex chromium particles with a mean diameter of 1398 . The smaller particles appear to be surrounded and amassed by some unidentified material, possibly an amorphous or extremely fine semiconducting chromium oxide such as $\mathrm{Cr}_{2} \mathrm{O}_{3}$. Some of the larger chromium particles are actually aggregates of very fine particles.

From these conclusions some generalizations can be made. The very small chromium particles are probably responsible for the high absorption in the visible wavelength range and might be described by an extension of the Maxwell-Garnett theory (as noted in Ref. 7). The transition region is not easily explained; it appears to depend upon the metallic substrate reflectance, coating thickness and possibly the size distribution of agglomerated chromium particles which, in turn, may depend upon the distribution of fine chromium. The reflectance after the transition region, in the infrared, suggests that the black chrome layer is ineffective and absorber reflectance is dictated by the underlying metal layer.

\section{Acknow ledgments}

The author wishes to thank Professor J. Washburn for his encouragement and guidance during this investigation. The author would also like to thank Mr. R. M. Drosd and Mr. G. R. Cunnington (Lockheed) for their respective help with electron microscopy and spectral reflectance measurements. The author acknowledges the Golden Gate chapter of the ASM for their travel fellowship swarded this manuscript.

The work was performed under the auspices of the U.S.Department of Energy through the Materials and Molecular Research Division of the Lawrence Berkeley Laboratory.

\section{References}

1. McDonald,G.E., "Spectral Reflectance Properties of Black Chrome for use as a solar Selective Coating," Solar Energy, Vol. 17, p.119. 1975.

2. Masterson, K. D. and Seraphin, B.O." "Inter-laboratory Comparison of the optical Characteristics of Selective surfaces for Photombermal Conversion of Solar Energy," NSF/RANN/SE/GI-36731X/TR/75/1. May 1975.

3. Pettit, R.B. and Sowel1,R.R., "Solar Absorptance and Emittance properties of Several Solar Coatings," J. Vac. Sci. Tech. "Vol. 13-2, p.596. 1976.

4. Mattox,D.M., Kominiak,G.H., Sowel1,R.R. and Pettit,R.B., "Selective Solar Photothermal Absorbers," SAND 75-0361. July 1975.

5. Lowery, J.R." "Solar Absorption Characteristics of Several Coatings and Surface Finishes," NASA TM X-3509. March $197 \%$

6. Robinson, N., Solar Radiation, P.81, Elsevier Publishing Co., Amsterdam, Netherlands. 1966.

7. Hogg, S.W. and Smith,G.B., "The Unusual and Useful optical Properties of Electrodeposited Chrome Black Films," J. of Physics D, Vo1. 10, p.1863. 1977.

8. McDonald,G。E, Buzek, B. and Curtis,Hop "Fundamental Studies of Black chrome for Solar collector Use," NASA TM X-73461. August 1976.

9. Keeling,M.C., Proceedings of the 1977 Annual Meeting of International Solar Energy Society, American Section, Orlando, Florida, pp.5-13. June 1979. 

This repont was done with support from the Department of Energy. Any conclusions or opinions expressed in this report represent solely. those of the author(s) and not necessarily those of The Regents of the Universily of California, the Lawrence Berkeley Laboratory or the Department of Inergy: 


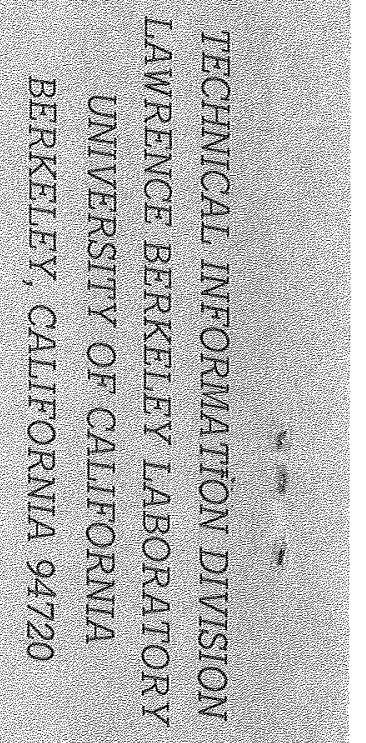

